\title{
Controle social, participação e representação no SUS estadual: um estudo de caso sobre o Conselho Estadual de Saúde do Rio de Janeiro (2003-2010)
}

\author{
Paulo Renato Flores Durán*
}

\begin{abstract}
Resumo
O objetivo do artigo é refletir sobre o papel social e político dos conselheiros estaduais de saúde do Rio de Janeiro. Através de pesquisa de campo sobre o Conselho Estadual de Saúde do RJ - entrevistas com conselheiros e ex-conselheiros e análise de documentos formais do Conselho -, procurou-se discutir os desafios da participação social de representantes da sociedade/usuários e profissionais de saúde vis-a-vis a estrutura política da Secretaria Estadual de Saúde. A análise dos dados da pesquisa mostrou que a arena deliberativa da política de saúde no Estado do Rio de Janeiro enfrenta dilemas próprios ao papel político do conselheiro e sua efetiva atribuição: o controle social. O artigo problematiza estes aspectos durante duas gestões governamentais (2003-2006 e 2007-2010), identificando traços de afinidades e de diferença nas relações sociais e políticas entre os conselheiros de saúde e os gestores da Secretaria Estadual. Aponta para os desafios de inserção de atores sociais na arena decisória das políticas de saúde no âmbito estadual; com isso, resgata as relações dessa tendência atual com a formação do campo político estadual do Rio de Janeiro. Por fim, procurou-se demonstrar que, ao mesmo tempo em que os conselheiros de saúde enfrentam entraves na integração de suas representatividades ao processo decisório de políticas; por outro lado, a construção da participação social refere-se à formação da cultura política própria ao sistema democrático.
\end{abstract}

Palavras-chave: participação social; controle social; Conselho de Saúde; políticas de saúde; democracia; processo decisório.

\begin{abstract}
The objective of this paper is to discuss the social and political role of the health council of Rio de Janeiro. Through field research on the Health Council of the RJ - interviews with councilors and analysis of formal documents of the Council - we tried to discuss the challenges of social participation of representatives of the society/users and health professionals vis-a-vis the political structure of the state Department of Health; analysis of the survey data showed that deliberative arena of health policy in the state of Rio de Janeiro, faces own political role of the counselor and their effective allocation dilemmas: social control. The paper discusses these aspects during two government administrations (2003-2006 and 2007-2010), identifying
\end{abstract}

* Cientista social, mestre em Ciências Sociais pela PUC-Rio, doutor em Ciência pela ENSP/FIOCRUZ e professor adjunto da PUC-Rio. E-mail: pauloduran@puc-rio.br. 
traces of affinities and differences in social and political relations between health counselors and managers of the State Department. Points to the challenges of inclusion of stakeholders in decision-making arena of health policy at the state level; thereby, relations rescues this current trend with the formation of the state political field of RJ. Finally, we sought to demonstrate that, while the council members face obstacles in the integration of its representativeness of political decision-making process; on the other hand, the construction of social interest refers to the formation of political culture fordemocratic system.

Keywords: social participation; social control; Health Council; health politics; democracy; policy making

\section{Apresentação}

Desde os anos 1990, os conselhos de saúde foram institucionalizados como arenas deliberativas das políticas de saúde nos três âmbitos da Federação (nacional, estadual e municipal). Apesar de inaugurarem um novo marco no processo decisório de definição das políticas de saúde, diversos impasses são apontados no que se refere a formação e aprofundamento da cultura política das instituições participativas da democracia brasileiras (Avritzer, 2007; Gerschman, 2004a). No caso dos conselhos de saúde, a falta de definição clara sobre o papel social e político das diversas representações conselheiras, a relação de indução política dos gestores das Secretarias de Saúde e a tendência à burocratização do controle social são alguns dos desafios enfrentados na legitimidade desses fóruns participativos (Gerschman, 2004a; Bispo Júnior e Gerschman, 2013).

Além disso, a formação de núcleos duros no âmbito do processo de decisão política tanto no interior dos conselhos de saúde, como no caso de comissões executivas, quanto em outros colegiados (como as Comissões Intergestores Bipartite e Tripartite ${ }^{1}$ ) - leva ao enfraquecimento das arenas de participação social (Côrtes, 2009b).

O objetivo deste artigo é analisar alguns dos dilemas concernentes à dinâmica da participação social do SUS no âmbito do Conselho Estadual de Saúde do Rio de Janeiro (CES/ RJ). O objetivo principal é analisar a atuação de representantes da sociedade/usuários e dos profissionais de saúde perante os atores estatais (gestores da Secretaria Estadual de Saúde do Rio de Janeiro - SES/RJ), durante os governos estaduais de Rosinha Garotinho (2003-2006) e Sérgio Cabral (2007-2010). Procura-se analisar como o CES/RJ se relaciona com a SES/RJ e em que medida existem entraves institucionais à participação social que se refletem nessa interação.

No caso do CES/RJ, os conselheiros representantes da sociedade e dos profissionais de saúde enfrentam os dilemas próprios à autonomização do sujeito político, que atua em uma arena política deliberativa fortemente institucionalizada e dirigida politicamente pelos gestores da SES/RJ. Ao mesmo tempo em que os conselheiros estaduais mobilizam o espaço político do CES/RJ em favor (ou na intenção) de discutir os impasses do SUS estadual, os avanços nas políticas de saúde são desvirtuados pela hegemonia claramente impressa pela atuação dos representantes da SES/RJ. Esse ponto marca uma diferença radical na forma 
como os secretários estaduais de saúde (Gilson Cantarino, no governo Rosinha, e Sergio Cortes, no governo Cabral) interagem e reagem às provocações dos conselheiros. $\mathrm{O}$ fato de que o projeto político do governo estadual seja levado adiante a reboque da participação social levou a pesquisa a considerar que os dilemas da efetiva participação social dos conselheiros representantes da sociedade e dos profissionais de saúde referem-se à possibilidade do exercício de fato de uma contra-hegemonia no processo de tomada de decisão política da saúde.

A pesquisa sobre o CES/RJ foi realizada entre 2009 e 2012. Foram entrevistados 19 conselheiros e ex-conselheiros estaduais de saúde, sendo 1 representante dos gestores e 1 dos prestadores de serviços (hospitais privados e filantrópicas), 7 dos profissionais de saúde (sindicatos e conselhos regionais) e 10 dos usuários/sociedade (entidades da sociedade civil, como, por exemplo, federação de associações de moradores, conselhos municipais, frações de movimentos sociais). Os representantes da sociedade entrevistados ocupavam as seguintes cadeiras no CES/RJ:

TABELA 1

Distribuição de conselheiros representantes da sociedade por cadeiras que ocupam

\begin{tabular}{l|c|c}
\hline REPRESENTANTES & FREQUÊNCIA & PERCENTUAL \\
\hline Associações de bairro & 4 & $21,1 \%$ \\
\hline Entidades de defesa dos direitos da mulher & 1 & $5,3 \%$ \\
\hline Conselhos Municipais de Saúde & 2 & $10,5 \%$ \\
\hline Portadores de deficiências / doenças & 2 & $10,5 \%$ \\
\hline TOTAL & 9 & $47,4 \%$ \\
\hline Não se aplica & 10 & $52,6 \%$ \\
\hline TOTAL & $\mathbf{1 9}$ & $\mathbf{1 0 0 \%}$ \\
\hline Fonte: Elaboração própria & &
\end{tabular}

Além desses atores, foi importante reportar-se à perspectiva dos gestores da SES/RJ e dos prestadores de serviços (filantrópicas, em especial). Dessa forma, a pesquisa pôde apontar para mútuas-visões entre os diferentes tipos de atores que participam do espaço público institucionalizado: o CES/RJ. De outra parte, os pontos de vistas desses atores permitem identificar e analisar as diversas formas através das quais as interações sociais no âmbito do CES/RJ refletem ou não o incremento da participação social.

\section{1 - O campo político estadual e da participação no Rio de Janeiro}

No âmbito estadual, a partir de 1970, ganha força política uma estrutura e um estilo de ação característicos do corte clientelista de modelação da prática política (ou, em outro sentido, uma forma na qual a indução das políticas por parte das instâncias executivas do poder se fortaleceu em detrimento e, muitas vezes, a reboque das bases sociais de representação). O personagem central, que dá o tom a essa prática, é Chagas Freitas (governador entre 1979-1983). Em estudo clássico sobre o Rio de Janeiro, Diniz (1982) diferencia as práticas próprias das agremiações partidárias (partidos políticos modernos) daquelas que denominou de máquina chaguista.

Rakove (1975), em estudo pioneiro sobre um novo estilo de ação e estruturação das políticas estaduais nos EUA, define a máquina política como ação coletiva de um grupo que se movimenta no sentido de facções políticas e não no sentido amplo dos modernos partidos políticos. As funções latentes (internas) da própria máquina política permitiriam seu 
desenvolvimento para além das questões coletivas; assim, tenderiam a favorecer interesses específicos de grupos aliados no que se refere às políticas urbano-sociais. A capacidade de capilarização da máquina em setores distintos do espaço urbano (igrejas, associações de vizinhança, clubes recreativos, entre outros) permitiria a criação de vínculos baseados em relações primárias de sociabilidade e não mediadas pelas instituições formais (partidos políticos). A máquina política funcionaria como partido político hegemônico; porém suas características internas de funcionamento difeririam dos princípios que geraram os modernos partidos políticos liberais:

QUADRO 1

Diferença entre máquina política e partido político

\begin{tabular}{c|c}
\hline MÁQUINA POLITICA & PARTIDO POLITICO \\
\hline Favores & Direitos \\
\hline Projeto de poder & Projeto político \\
\hline Benfeitorias & Cidadania \\
\hline Particularismo & Universalismo \\
\hline Clientela & Cidadão \\
\hline
\end{tabular}

A organização político-organizativa da máquina chaguista, segundo Diniz, se estabelece, principalmente, a partir de 1970. É nesse período, também, que a chefia política, marcada pelo personagem Chagas Freitas, favorece a proximidade de certo estilo de ação e estrutura de governo com algumas características fundamentais da máquina política:

- oligarquização partidária (no caso, o MDB);

- relação de proximidade (patronagem e clientelismo) entre políticos chaguistas e bairros, favelas, associações religiosas, de profissionais, de moradores, escolas de samba etc.; - estrutura da máquina delimitada por áreas de influência, formando as chamadas redes clientelistas entre os políticos e entre estes e os cidadãos comuns.

Dessa forma, os atos e poderes dos governadores subvertem a lógica do equilíbrio entre poderes, na medida em que suas iniciativas ficam imunes mesmo a qualquer fiscalização institucional (seja ela proposta pelo Legislativo ou pelos órgãos de controle externo, como os Tribunais de Conta, por exemplo; assim como a lógica da participação da sociedade). De forma assemelhada às características da chefia política, os governadores maximizam suas chances de primazia na condução de projetos políticos de sua cúpula partidária, na medida em que alcançam maiorias no Legislativo estadual. Com isso, o processo de institucionalização da arena deliberativa e participativa do CES/RJ encontrou-se com uma formação frágil de reconhecimento da participação social nas arenas de tomada de decisão política. Esse ponto já havia, também, sido ressaltado na pesquisa de Gerschman, quando afirma que "a efetividade dos Conselhos relaciona-se à pressão exercida pelos usuários, pelos movimentos sociais organizados e profissionais de saúde e à maior proximidade da população com as autoridades locais" (Gerschman, 2004a:244).

Criadas juntamente com os colegiados de participação social (conselhos de saúde), nos anos 1990, as comissões intergestores, segundo alguns pesquisadores, acabaram tornando-se espaços privilegiados de tomada de decisão no âmbito do Estado, e com isso o papel político e deliberativo dos conselhos de saúde secundarizou-se (Côrtes, 2009a, 2009b; Silva, 2000; Silva e Labra, 2001). Assim, Santos e Gerschman ressaltam que a criação das comissões in- 
tergestores afetou negativamente o funcionamento das arenas deliberativas dos conselhos de saúde e sua capacidade de se tornarem fóruns centrais de decisão sobre as escolhas de políticas de saúde (Santos e Gerschman, 2006:182).

\section{2 - Aspectos da participação social no âmbito do Conselho Estadual de Saúde do RJ}

As inovações institucionais que viabilizaram a institucionalização dos conselhos de saúde no SUS foram costuradas através da lei orgânica do SUS, Lei 8142/90, e possibilitaram a imbricação entre controle social, participação e representação política da sociedade nas arenas de decisão sobre políticas de saúde. Além desta, as resoluções editadas pelo Conselho Nacional de Saúde (por exemplo, a 333/03 e 453/12²), normatizaram a forma através da qual os conselhos de saúde - nas três esferas da Federação - deveriam funcionar e estruturar-se. Muito embora a institucionalização dos conselhos de saúde representar avanço significativo da democracia brasileira, depois de duas décadas de enraizamento na realidade sociopolítica de estados e municípios, ainda persistem intensos dilemas quanto à legitimidade dos atores que efetivam alguns dos modos de representação nesses espaços ou arenas políticas de deliberação. Os dilemas do controle social e da participação referem-se à própria formação de sujeitos políticos partícipes das arenas políticas (Gerschman, 2004a e 2004b).

A composição atual do CES/RJ (Labra, 2010:104) está dividida em quatro segmentos de atores: gestores e prestadores de serviço, profissionais de saúde e sociedade. Tomando-se por base a divisão paritária dos conselhos de saúde - e tendo como referência a Lei 8142/90 e a Resolução 333/03 do Conselho Nacional de Saúde -, pode-se dizer que a atual composição do CES/RJ vem trabalhando com a ideia de reconhecimento do trabalho integrado de uma pluralidade de atores - muito embora, isso seja apenas uma definição primária de análise. O Gráfico 1 procura dar conta da distribuição das cadeiras no CES/RJ entre diferentes tipos de atores: 
GRÁFICO 1

Distribuição de atores por entidades no CES/RJ*

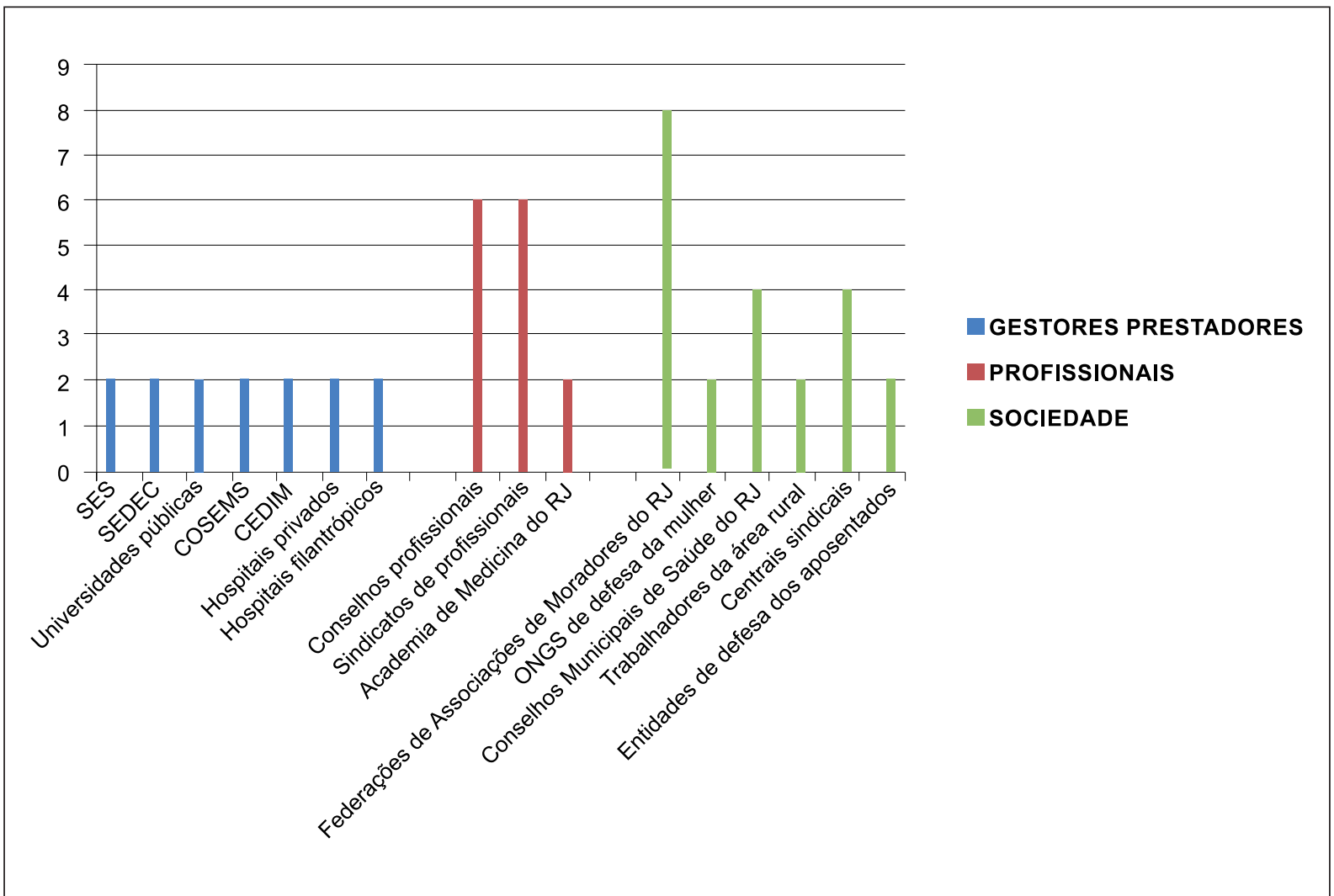

* As siglas das instituições mencionadas neste gráfico são respectivamente: SES - Secretaria Estadual de Saúde; SESDEC - Secretaria Estadual de Saúde e Defesa Civil; COSEMS - Conselho de Secretarias Municipais de Saúde do Estado do Rio de Janeiro; CEDIM - Conselho Estadual dos Direitos da Mulher/RJ. Fonte: Elaboração própria.

Quanto à distribuição desses assentos por segmento representado, pode-se observar uma distribuição equânime dos atores, assim como uma diversidade de instituições e organizações que compõem o CES/RJ, fato que se estende entre as duas gestões governamentais. De fato, há um processo de democratização da participação no âmbito do CES/RJ, ainda que não seja possível afirmar que há processo de construção democrática no nível do processo deliberativo, compartilhado pelos diversos segmentos representativos de atores sociais, de mercado e de governo (Côrtes, 2009b). Ou seja, apesar de representar uma paridade equânime entre atores diversos - como proposto na Lei 8142/90 e nas Resoluções do CNS -, da perspectiva sociológica não se pode afirmar que a paridade per se garante a legitimidade das representações dentro do espaço público. Quanto à participação dos conselheiros no âmbito das comissões internas do CES/RJ, obtivemos a seguinte distribuição:

TABELA 2.

Distribuição de conselheiros por comissão interna do CES/RJ da qual participam*

\begin{tabular}{c|c|c}
\hline COMISSÃo & FREQUÊNCIA & PERCENTUAL \\
\hline Comissão Executiva & 5 & $31,3 \%$ \\
\hline Comissão de Qualidade e Gestão & 4 & $25,0 \%$ \\
\hline Comissão de Vigilância em Saúde & 4 & $25,0 \%$ \\
\hline Comissão de Legislação & 3 & $18,8 \%$ \\
\hline
\end{tabular}

Cada conselheiro pode participar de mais de uma comissão

Fonte: Elaboração própria.

Quando perguntados sobre qual é o papel de cada uma das comissões internas do CES/RJ, os entrevistados responderam que a função mais importante dessas comissões é en- 
caminhar demandas da sociedade (com 73,7\% que atribuem muito importante a essa questão), seguida por discussão de questões específicas (com 68,4\%), deliberar sobre questões específicas e propor pautas (ambas com 41,1\%). Para os conselheiros, as discussões e propostas das comissões internas têm papel importante para o processo decisório sobre as políticas de saúde; muito embora não se possa afirmar o mesmo sobre a percepção desses atores quanto aos aspectos dialógicos que se efetivam nas reuniões plenárias do CES/RJ.

Apesar disso, os conselheiros entrevistados afirmam existirem documentos que regulamentam o papel do conselheiro (89,5\%). Desse total, 64,7\% dos entrevistados mencionaram o Regimento Interno como documento que esclarece as competências dos conselheiros de saúde. Além do Regimento, 35,3\% dos entrevistados mencionaram as leis de criação do CES/RJ; 23,5\% mencionaram as Resoluções do CNS e 11,8\% indicaram as leis orgânicas do SUS, portarias e recomendações do Ministério da Saúde como parâmetros das e para as atividades que concernem aos conselheiros de saúde.

A interação dos conselheiros estaduais com outros segmentos representativos é outro dado importante e que revela, segundo os entrevistados, relações pouco estabelecidas e/ou definidas entre as representações conselheiras. Na Tabela 3 pode-se depreender o grau de interação entre alguns dos grupos de conselheiros:

TABELA 3

Grau de interação entre representantes do CES/RJ e os gestores da SES/RJ

\begin{tabular}{c|c|c|c|c}
\hline GRAU DE INTERAÇÃ0 & $\begin{array}{c}\text { Usuários e portadores de do- } \\
\text { enças específicas e gestores }\end{array}$ & $\begin{array}{c}\text { Associações de bairros e } \\
\text { favelas e gestores }\end{array}$ & $\begin{array}{c}\text { Setor privado e gestores } \\
\text { Profissionais de saúde e } \\
\text { gestores }\end{array}$ \\
\hline De 0-4 & $21,1 \%$ & $5,3 \%$ & $5,3 \%$ & $36,8 \%$ \\
\hline De 5-7 & $26,3 \%$ & $42,1 \%$ & $5,3 \%$ & $68,4 \%$ \\
\hline De 8-10 & $47,4 \%$ & $36,8 \%$ & $78,9 \%$ & $5,3 \%$ \\
\hline TOTAL & $94,7 \%$ & $84,2 \%$ & $21,1 \%$ & $84,2 \%$ \\
\hline Não sabe & $5,3 \%$ & $15,8 \%$ & $100 \%$ & $15,8 \%$ \\
\hline TOTAL & $100 \%$ & $100 \%$ & $100 \%$ \\
\hline
\end{tabular}

Fonte: Elaboração própria.

Enquanto entre os representantes da sociedade (usuários e portadores de doenças específicas e associações de bairros e favelas) e os representantes dos profissionais de saúde pode-se perceber uma flutuação nos diferentes graus de interação com os gestores da SES/RJ; não deixa de ser perceptível o fato de que os representantes do setor privado tendam a uma avaliação mais positiva em relação à sua interação com os gestores. Perguntados acerca da percepção sobre o papel que o CES/RJ deveria desempenhar perante a SES/RJ, os conselheiros entrevistados mencionaram os seguintes tipos de papéis:

TABELA 4

Percepção do papel do CES/RJ perante a SES/RJ*

\begin{tabular}{c|c|c}
\hline TIPO DE PAPEL & FREQUÊNCIA & PERCENTUAL \\
\hline Fiscalização & 14 & $77,8 \%$ \\
\hline Deliberar a política de saúde & 8 & $42,1 \%$ \\
\hline Papel crítico em relação as ações da SES/RJ & 7 & $36,8 \%$ \\
\hline Outros & 2 & $10,5 \%$ \\
\hline
\end{tabular}

* Cada conselheiro pode responder mais de um tipo de papel

Fonte: Elaboração própria.

Apesar disso, os conselheiros estaduais de saúde demonstram pouca satisfação com as condições de diálogo durante as reuniões plenárias. Esse dado da pesquisa é interessante, 
porque revela que, se os conselheiros atribuem papel importante às discussões internas das comissões, por outro lado, revelam que o espaço das reuniões plenárias não refletiria o processo de discussão política sobre as demandas da sociedade:

TABELA 5

Satisfação com as condições de diálogo nas reuniões plenárias

\begin{tabular}{c|c|c}
\hline SATISFAÇÃO & FREQUÊNCIA & PERCENTUAL \\
\hline Sim & 5 & $26,3 \%$ \\
\hline Não & 14 & $73,7 \%$ \\
\hline TOTAL & 19 & $100 \%$ \\
\hline
\end{tabular}

Os motivos para a não satisfação dos conselheiros com as condições de diálogo nas reuniões plenárias do CES/RJ podem ser distribuídos da seguinte forma - considerando-se que cada conselheiro poderia responder mais de um motivo: 35,7\% atribuem sua não satisfação ao debate esvaziado; $50 \%$ atribuem o motivo a conflitos internos - entre os próprios conselheiros e com a gestão; e 21,4\% atribuem o motivo à ausência de diálogo, principalmente quando se referem à atuação dos gestores da SES/RJ na reuniões plenárias.

Assim, em termos qualitativos, quanto ao papel que o CES/RJ deveria ocupar perante a SES/RJ, as próprias atividades do Conselho são representadas pelos conselheiros de diversas formas. Num primeiro grupo de respostas, encontramos aquelas que associam o papel do CES/RJ às ideias de fiscalização e cobrança das ações dos gestores:

\footnotetext{
Órgão fiscalizador das ações da SES; proponente de estratégias de ações no interesse público. (Entrevistado representante dos profissionais)

Fiscalizar os atos da SES, construir com ela o plano plurianual e a agenda anual e quadro de metas, o orçamento e, caso haja descumprimento, comunicar as irregularidades às autoridades a nível estadual e federal. (Entrevistado representante da sociedade)
}

Em um segundo grupo de respostas, os conselheiros estaduais de saúde ressaltam o papel do CES/RJ como arena de participação e construção compartilhada das políticas públicas. Dessa forma, ressaltam que o papel a que se dedica o conselheiro de saúde vai mais além da pura fiscalização ou cobrança dos atos do gestor de saúde; segundo alguns dos conselheiros entrevistados, faz parte do papel social do conselheiro monitorar e avaliar criticamente os trabalhos dos gestores da SES/RJ. Ressalte-se, nesse aspecto, que vários ex-conselheiros apresentaram visão diversa: na gestão do secretário Gilson Cantarino, havia “mais entrada” e mais diálogo dos conselheiros com a SES/RJ; enquanto que, na gestão de Sergio Cortes, para vários conselheiros, os vínculos com a Secretaria são rarefeitos - parecendo que "dois mundos", separados e dissociados, apartam a vida do CES/RJ da vida dos gestores.

Essa percepção diferenciada entre as duas gestões governamentais pode ser visualizada quando os conselheiros foram perguntados sobre a satisfação de demandas pela SES/ RJ. Enquanto para os atores representantes das entidades de bairros e favelas há uma clara diferença entre a gestão de Gilson Cantarino e a de Sergio Cortes, para os atores representantes dos hospitais privados e filantrópicas parece não haver muitas diferenças na consecução de seus interesses: 
TABELA 6

Percepção dos conselheiros sobre efetivação de demandas

\begin{tabular}{l|c|c}
\hline $\begin{array}{l}\text { PERCEPÇÃO DO CONSELHEIRO SOBRE EFETIVAÇÃO } \\
\text { DE DEMANDAS }\end{array}$ & ENTIDADES DE BAIRROS E FAVELAS & HOSPITAIS PRIVADOS E FILANTRÓPICAS \\
\hline A anterior era mais receptiva que a atual & $31,6 \%$ & $31,6 \%$ \\
\hline A anterior era menos receptiva que a atual & $10,5 \%$ & $0 \%$ \\
\hline Não há diferença entre a anterior e a atual & $15,8 \%$ & $21,1 \%$ \\
\hline TOTAL & $57,9 \%$ & $52,6 \%$ \\
\hline Não se aplica & $36,8 \%$ & $36,8 \%$ \\
\hline Não sabe / não respondeu & $5,3 \%$ & $10,5 \%$ \\
\hline TOTAL & $100 \%$ & $100 \%$ \\
\hline Fonte: Elaboração própria. & & \\
\hline
\end{tabular}

Nesse sentido, para os conselheiros entrevistados, 73,7\% afirmam que algum grupo ou associação acumula mais poder do que outros no âmbito do CES/RJ) (enquanto 26,3\% afirmam que não há acúmulo de poder). Entre os grupos que acumulam mais poder estão os usuários (76,9\%) e os gestores da SES/RJ (46,2\%). Perguntados sobre os motivos pelos quais esses grupos acumulam mais poder do que outros, os conselheiros apontaram para os seguintes dados:

TABELA 7

Motivo pelo qual grupos acumulam mais poder do que outros*

\begin{tabular}{l|c|c}
\hline MOTIVOS & FREQUÊNCIA & PERCENTUAL \\
\hline Pela representatividade e participação & 6 & $54,5 \%$ \\
\hline Pela articulação política e interesses da gestão & 5 & $45,5 \%$ \\
\hline Pelo histórico de participação & 4 & $36,4 \%$ \\
\hline
\end{tabular}

* Cada conselheiro pode responder mais de um motivo

Fonte: Elaboração própria.

Os dados da Tabela 7 são importantes porque, se, por um lado, indicam que a justificativa para o acúmulo de poder por alguns grupos ou associações se dá pela questão da representatividade (maior número de representantes da sociedade, por exemplo) ou pela articulação política de alguns atores com a gestão governamental; por outro lado, indicam que passa despercebido o histórico de participação e o papel político de algumas entidades sociais na configuração do campo político do RJ.

Perguntados sobre a questão da capacidade de conselheiros representantes da sociedade para tomarem parte no processo decisório, 31,6\% respondeu que estes estão capacitados; enquanto $68,4 \%$ respondeu que não. Os motivos para a falta de capacitação dos conselheiros participarem do processo decisório são: 61,5\%, falta de capacitação / educação permanente; $38,5 \%$, falta de independência política para decidir; e 46,2\%, falta de conhecimento sobre o papel do conselheiro.

Nesse sentido, os entrevistados também divergem na avaliação que fazem das duas gestões governamentais: se, na gestão do secretário Gilson Cantarino, havia "mais liberdade" de trabalho para os conselheiros ("formação de uma agenda própria ao CES/RJ, elaborada pelos conselheiros”), na gestão de Sergio Cortes, há uma clara impressão de que a agenda política do CES/RJ "depende" do que colocam os gestores da SES/RJ como pontos de pauta para o processo deliberativo dos conselheiros. Ou seja, se, na gestão Rosinha, podemos afirmar que houve intenção do secretário de saúde de autonomizar os trabalhos do CES/RJ, por exemplo, na formação de sua própria agenda política; na gestão Cabral, o Conselho fica "amarrado" por uma decisão ex ante dos gestores da SES/RJ, na visão de entrevistados representantes da sociedade e dos profissionais de saúde. 
Em diversas tomadas de posição, os conselheiros estaduais de saúde, durante o governo Cabral, levantaram a questão crítica de que as atividades próprias do Conselho estão subordinadas à SES/RJ, causando bloqueios para o exercício do controle social. Essa questão está associada à confusão que se criou a partir da ausência de definições claras sobre a autonomia dos trabalhos dos conselheiros. A autonomia requerida pelos conselheiros refere-se ao reconhecimento de seu papel no processo de tomada de decisão e aos contornos do papel de conselheiro.

A perspectiva de falta de autonomia política do conselheiro é marcante no período do governo Cabral. A partir de alguns registros e análises de Atas de Reuniões Plenárias do CES/ RJ, ressalta-se que, na visão dos gestores da SES/RJ, 80,8\% dos entrevistados afirmam que as reuniões com o CES/RJ não se configuram como espaços para a tomada de decisão; só 11,5\% afirmaram que o Conselho participa dos mecanismos de tomada de decisão. Em relação com esse tópico, e sendo o secretário estadual de saúde também presidente do CES/RJ, 73,1\% dos gestores afirmam que a participação do secretário nas reuniões com os conselheiros estaduais de saúde não é procedimento para tomada de decisão do Poder Executivo.

Referindo-se à composição de representatividades no CES/RJ, mas refletindo sobre a tomada de decisão dentro do processo deliberativo, o conselheiro representante da sociedade ressalta que "às vezes os interesses são voltados não para a maioria e sim para os interesses particulares [do governo estadual], principalmente quando envolve recurso financeiro" (Entrevistado representante da sociedade). Este dado não só corrobora o tipo de relação de poder ainda pouco ascendente estabelecida entre representantes dos gestores da SES/RJ, de um lado, e da sociedade e profissionais de saúde, de outro, mas também se refere ao modo como são encaminhadas as deliberações no âmbito do Conselho. Ou seja, são transformadas em Resoluções pelo secretário de saúde aquelas deliberações que se referem aos temas de interesse da gestão. Esse fato diverge da visão que ex-conselheiros têm de como a gestão do secretário Gilson Catarino trabalhava: não só havia "mais autonomia de ação" no Conselho, como "era o próprio secretário quem recebia a agenda formulada pelos conselheiros" (Entrevistada representante dos gestores/prestadores).

Diante da questão sobre como percebem que os gestores da SES/RJ ouvem, respeitam e acatam as deliberações do CES/RJ, 57,9\% responderam que sim, enquanto 36,8\% responderam negativamente a essa questão. Esses dados refletem, também, a forma como diferentes formações da SES/RJ trabalham com os conselheiros: se, por um lado, os conselheiros que fizeram parte da gestão de Gilson Cantarino afirmam que os gestores ouviam, respeitavam e acatavam as deliberações do Conselho e incluíam o trabalho dos conselheiros na própria formulação da agenda política da SES/RJ; por outro lado, os conselheiros da gestão de Sergio Cortes afirmaram o contrário - ou seja, que a SES/RJ ouvia, mas não respeitava e acatava as agendas propostas pelos conselheiros.

Fato interessante é que, no período da gestão de Sergio Cortes, as respostas justificativas para a consideração de que a SES/RJ ouve, respeita e acata as deliberações do CES/RJ podem ser arroladas como uma forma de explicitação de como os gestores "ouvem e respeitam, mas não acatam” (Entrevistado representante dos profissionais).

Se na gestão de Gilson Cantarino, para 30,4\% dos ex-conselheiros entrevistados, o CES/RJ utiliza procedimentos democráticos de consulta à sociedade, na gestão de Sergio Cortes para 60,9\% dos conselheiros, o Conselho não faz quaisquer tipos de consulta à sociedade. Os conselheiros que responderam positivamente à questão ressaltam, principalmente, as Conferências de Saúde como canal democrático pelo qual os Conselhos se aproximam das 
demandas da sociedade. Essa prática estaria mais próxima da criação de laços fortes entre os atores - gestores e prestadores, profissionais de saúde e sociedade. Enquanto isso, na gestão de Sergio Cortes, por ocasião da Conferência Estadual de Saúde em 2011, os conselheiros experimentaram uma arquitetura política que, no limite, encerrou a própria participação popular na plenária; o que, na construção de vínculos de solidariedade e reciprocidade entre os atores, poderia ser percebida como laços fracos. ${ }^{3}$

Na ênfase dada pelos conselheiros entrevistados, na gestão Cabral, o CES/RJ está muito afastado das demandas da sociedade e, no limite, como ressalta um entrevistado, "o governo do estado tem por prática não consultar a sociedade; tem uma política autoritária” (Entrevistado representante dos profissionais). Essa percepção crítica estende-se, ainda, ao processo inconcluso a que alguns conselheiros referem-se ao tematizar a ausência de tratamento que os gestores da SES/RJ dão aos resultados das Conferências de Saúde. A gestão da SES/RJ, como relata um conselheiro, "não respeita as decisões da conferência" (Entrevistado representante dos profissionais).

Há uma percepção entre os conselheiros de que o mecanismo de troca de informações entre a gestão e o CES/RJ é incompleto. Ou seja, se os documentos da gestão (como o Plano Estadual de Saúde, os Relatórios Anuais de Gestão) devem ser aprovados por processo deliberativo nas Reuniões Planárias do CES/RJ, esses nunca são explicitados no Conselho e, quando chegam aos conselheiros, já estão prontos e aprovados - de que é exemplo o registro de um conselheiro numa das Reuniões Plenárias: os conselheiros só aprovam pacotes prontos (são 36,4\% dos entrevistados que responderam que a SES/RJ já traz ideias prontas para o processo deliberativo). De outra parte, $27,3 \%$ dos conselheiros entrevistados afirmam que os gestores da SES/RJ não respeitam as decisões tomadas, nem nas reuniões plenárias do CES/ RJ nem no âmbito das Conferências de Saúde. Com isso, 52,6\% dos conselheiros respondem afirmativamente para a pergunta sobre se há mecanismos de consulta entre os gestores e os conselheiros fora das reuniões plenárias.

No limite, esse registro é demonstrativo da percepção dos gestores da SES/RJ de que o trabalho dos conselheiros estaduais "não acompanha as necessidades da sociedade em razão da pouca politização do CES” (Entrevistado representante da SES/RJ). Assim, em geral, há uma baixa percepção de que o CES/RJ exerce o controle social (53,8\% respondem negativamente ao exercício do controle social):

TABELA 8

Exercício do controle social, segundo os gestores

\begin{tabular}{c|c}
\hline O CES/RJ EXERCE 0 CONTROLE SOCIAL & GESTORES (PERCENTUAL) \\
\hline Sim & $34,6 \%$ \\
\hline Não & $53,8 \%$ \\
\hline Não sabe / não respondeu & $11,6 \%$ \\
\hline TOTAL & $100 \%$ \\
\hline
\end{tabular}

As justificativas para essa percepção pessimista sobre o CES/RJ são principalmente as que constam na Tabela 9, associadas a percentuais decrescentes. O que se apresenta abaixo são dados que indicam uma visão cética em relação à participação social no processo de construção das políticas de saúde no Estado do RJ: 
TABELA 9

Motivos do não controle social do CES/RJ*

\begin{tabular}{c|c}
\hline O CES/RJ EXERCE 0 CONTROLE SOCIAL & GESTORES (PERCENTUAL) \\
\hline Representação limitada & $66,7 \%$ \\
\hline Pouco qualificado & $61,9 \%$ \\
\hline Demasiado partidarizado & $47,6 \%$ \\
\hline Faltam representantes de vários setores & $23,8 \%$ \\
\hline
\end{tabular}

podiam apontar para mais de uma opção do questionário

Fonte: Elaboração própria.

No sentido da representação política, segundo Pitkin, a ideia original contida na fórmula "agir em nome de" (acting for) precisa levar em consideração "o quê" e "como" o representante realiza a deliberação ao tomar para si a relação com seus representados (Pitkin, 1997:143). Nos termos do debate rawlsiano, a questão estabelece que o sujeito que representa guarda consigo a própria "ideia de bem" que espelha as demandas daqueles que são seus reais mandatários. Assim, a figura do conselheiro seria, em última instância, aquela que expressa, no debate público, os anseios e desejos, interesses e disputas, de uma fração específica do demos. O problema colocado pela acepção rawlsiana de justiça como equidade refere-se a que "a participação do demos exige muito mais que um ato de autorização ou escolha de representantes e deve ir muito além dos procedimentos eleitorais” (Bispo Júnior e Gerschman, 2013:10). Isto é, a deliberação precisa ser analisada em termos de processo que leva os atores a formas variadas de relações sociopolíticas; a simples descrição procedimental do funcionamento de uma esfera pública (Dahl, 2005; Rawls, 2000) limita a análise e o escopo a que se poderia chegar, não atentando para o fato de que as arenas de poder geram relações de aliança e conflito.

\section{3 - Relações entre os conselheiros estaduais e a gestão da SES/RJ: mútuas-visões e conflitos}

A análise das mútuas-visões construídas entre os conselheiros estaduais representantes da sociedade e dos profissionais de saúde e os gestores da SES/RJ possibilitou identificar como os antagonismos se estabelecem nos espaços próprios ao processo deliberativo. Se, por um lado, é notório o conflito aberto entre conselheiros e gestores, fruto de uma inscrição tardia do processo participativo no campo político do Rio de Janeiro (Boschi, 1987; Diniz, 1982; Gerschman, 2004a; Labra, 2010), por outro lado, é necessário identificar que tipo de visão gestores e conselheiros constroem acerca desse embate. Essas visões refletem, do ponto de vista dos gestores, como o Estado se relaciona com a sociedade e lhe empresta papel político no processo deliberativo de políticas de saúde. Dessa forma, através de registros das entrevistas com conselheiros e gestores, em geral, identificou-se a fragilidade com que os conselheiros estaduais de saúde no RJ mobilizam o espaço do Conselho na prática efetiva do controle social - apesar da animação política do espaço do CES/RJ na gestão de Gilson Cantarino. Conforme já mencionado, esse espaço não se reduziria somente a uma prática fiscalizatória, mas deveria levar adiante um debate crítico com os representantes do governo estadual de forma tal que as escolhas políticas fossem compartilhadas e espelhassem as demandas da sociedade. Ademais, a esfera de atuação do próprio conselheiro é demarcada pelos usos possíveis que esse sujeito político faz dos documentos produzidos pelos gestores da SES/RJ.

Nesse sentido, as fontes documentais produzidas pelos gestores da SES/RJ compõem o que, em nível federal, chama-se Sistema de Planejamento do SUS (PlanejaSUS). Esse sistema 
procura "pactuar diretrizes gerais para o processo de planejamento no âmbito do SUS e os instrumentos a serem adotados pelas três esferas de gestão" (Brasil, 2006). A necessidade de um sistema integrado e pactuado de planejamento das políticas de saúde nos três âmbitos da Federação justifica-se pelo fato de que a atividade de elaboração desses instrumentos deveria conferir um caráter de base local e ascendente na definição de ações políticas programáticas, ou seja, partir dos problemas locais, expressos em diagnósticos que norteiam a elaboração dos três instrumentos de gestão, ${ }^{4}$ os quais atuam de forma integrada.

Ou seja, a cada quatro anos - na vigência de uma nova gestão governamental -, o Plano Estadual de Saúde (PES) deve ser o primeiro documento colocado em pauta no âmbito do processo deliberativo no CES/RJ. Para que o PES seja monitorado e avaliado continuamente, durante os quatro anos de uma gestão governamental, os conselheiros precisam receber, analisar, emitir pareceres e aprovar em Reunião Plenária os Relatórios Anuais de Gestão (RAGs) e as Programações Anuais de Saúde (PASs).

A aprovação/homologação desses instrumentos de gestão deve, portanto, ser realizada no espaço das Reuniões Plenárias dos Conselhos de Saúde. Como já apontado anteriormente, no âmbito do CES/RJ, considerando-se a percepção dos gestores da SES/RJ, há uma avaliação cética em relação ao funcionamento da arena deliberativa do CES/RJ:

TABELA 10

Funcionamento do CES/RJ na ótica do gestor da SES/RJ

\begin{tabular}{c|c}
\hline FUNCIONAMENTO DO CES/RJ & GESTORES (PERCENTUAL) \\
\hline Amplamente satisfatório & $2,6 \%$ \\
\hline Satisfatório & $41 \%$ \\
\hline Medianamente satisfatório & $35,9 \%$ \\
\hline Insatisfatório & $12,8 \%$ \\
\hline Não sabe/não respondeu & $7,7 \%$ \\
\hline TOTAL & $92,3 \%$ \\
\hline
\end{tabular}

Fonte: Elaboração própria.

Entre alguns gestores, a própria postura isolacionista de alguns conselheiros seria reflexo de "ações isoladas e corporativistas que bloqueiam" os trabalhos compartilhados entre gestores e conselheiros (Entrevistado representante dos gestores da SES/RJ). Dessa maneira, segundo os gestores, a prática corporativista dentro do CES/RJ aliena a arena deliberativa e torna inoperante o processo de tomada de decisão política. Ressalta-se que o corporativismo a que se referem os gestores classificaria os atores constituintes do CES/RJ dentro da chave pluralista, onde por último grupos de interesse buscam alcançar de forma competitiva resultados isolados para seus segmentos (Labra, 1999:154). Dessa maneira, os grupos de conselheiros (como os profissionais de saúde e os representantes da sociedade) ocupariam, por meio de pressões, lugares de determinação de preferências políticas, desconsiderando que a estrutura da arena deliberativa leva a decisões conjuntas relacionadas às demandas da sociedade. Ou seja, para alguns dos gestores, longe de agir através do modelo associativo, os conselheiros utilizariam o espaço de deliberação na via da concertação organizacional (Streeck e Schmitter, 1985). O poder de barganha definiria, em último caso, as preferências em jogo, ao conceber a arena deliberativa como mercado político. Por fim, seria o contexto

4 Os três instrumentos de gestão que devem ser produzidos nas três esferas da Federação (pelas Secretarias de Saúde, municipais e estaduais, e pelo Ministério da Saúde) são: (1) Plano de Saúde (PS) - elaborado a cada quatro anos, é composto pelas diretrizes principais do governo; (2) Relatório Anual de Gestão (RAG) - expressão das atividades efetivadas pelo gestor anualmente e deve dar sequenciamento ao Plano de Saúde; (3) Programação Anual de Saúde (PAS) - ao lado do Relatório Anual, refere-se à descrição de como o gestor investiu a verba orçamentária destinada às ações em saúde. Esses instrumentos de gestão devem ser submetidos às Reuniões Plenárias dos Conselhos de Saúde, discutidos e aprovados pelos conselheiros. 
estratégico oferecido pela própria estrutura institucional (SES/RJ) aquele que oferece as janelas de oportunidade para a maximização dos interesses. Essa visão acerca dos conselheiros estaduais assemelha-se não só ao viés pluralista de análise da interação entre os atores, mas também lançaria mão da pressuposição da escolha racional dos indivíduos. Ao contrário de escolhas baseadas em critérios de princípios de justiça (fairness), os atores agiriam conforme critérios baseados na escolha individualista

Essa análise espelharia o modelo olsoniano, em que os indivíduos não se inseririam em ações coletivas de tipo cooperativas; este engajamento pressuporia que os grupos de interesse alcancem ou maximizem seus benefícios a reboque dos resultados coletivos. Na ótica dos gestores da SES/RJ, esse modo de agir leva à impressão de que "a participação social não tem acompanhado as necessidades da sociedade em razão da pouca politização do CES” (Entrevistado representante dos gestores da SES/RJ).

Nas entrevistas com os gestores, perguntou-se que tipo de papel eles achavam que os conselheiros ocupam no processo decisório. De uma parte, salienta-se uma relação com as respostas dos conselheiros de que as relações/interações entre segmentos são pouco definidas ou influenciam pouco; de outra parte, ficou evidenciado também que uma parte dos gestores atribuem pouca significação ao papel de controle/fiscalização dos conselheiros $(14,3 \%)$, enquanto outros afirmam positivamente esse papel dos conselheiros (85,7\%). Com isso, assumem a visão de que a participação desses atores no processo decisório está relacionada à aprovação de propostas de planejamento (ou seja, aprovação/homologação dos documentos da gestão, como os Relatórios Anuais de Gestão, entre outros).

$\mathrm{Na}$ forma como é colocada a participação dos conselheiros no processo decisório, 76,9\% dos gestores acreditam que o CES/RJ contribui com o trabalho da SES/RJ; enquanto que $23,1 \%$ afirmam que os conselheiros pouco influenciam na gestão. As raízes dessas percepções precisam ser colocadas sob uma visão, essa sim compartilhada entre gestores e conselheiros, de que faltam informações necessárias para o processo de tomada de decisão. Estas poderiam ser uma rica fonte de incremento do papel do conselheiro no processo de tomada de decisões políticas. Há uma ênfase, da parte dos conselheiros entrevistados, no que se refere aos mecanismos que potencializariam o trabalho deles perante a SES/RJ, ensejandose a necessidade de uma programação de educação permanente do ator.

Toda falta de informações (jurídicas e técnicas, por exemplo) levaria à percepção de que os conselheiros estaduais de saúde, para 65,2\% dos gestores entrevistados, não estariam suficientemente capacitados para tomarem decisões. Na visão de dois gestores, aos conselheiros faltaria "visão do processo" (Entrevistado representante dos gestores da SES/ RJ), o que inviabilizaria uma discussão mais aprofundada entre os atores acerca do "papel do controle social” (Entrevistado representante dos gestores da SES/RJ). A proporção entre os conselheiros estaduais de saúde que percebem a falta de capacidade dos segmentos representantes da sociedade, principalmente, para tomar decisões, é igual àquela atribuída pelos gestores.

Dessa forma, entre os conselheiros entrevistados, há uma visão de que o controle social não se efetiva porque, por um lado, há um jogo de interesses políticos efetivado pelos gestores em relação a algumas representações conselheiras (em nível municipal e/ou estadual); de outra parte, como ressalta um representante dos profissionais, "há cerceamento do direito de voz; [o CES/RJ] encaminha matérias de interesse da gestão, polêmicas e sem discussão prévia" (Entrevistado representante dos profissionais). Esse "cerceamento da voz" é representativo de um bloqueio efetivado pelo gestor no encaminhamento de questões po- 
lêmicas que dizem respeito às demandas da sociedade. Em última instância, entre os conselheiros estaduais de saúde, a forma como a gestão conduz (ou induz) os trabalhos dentro do CES/RJ impede que se cumpram com as competências próprias do conselheiro de saúde.

TABELA 11

0 CES/RJ cumpre com seu Regimento Interno (R.I.) e exerce o controle social?

\begin{tabular}{c|c|c}
\hline $\begin{array}{c}\text { 0 CES/RJ CUMPRE COM SEU R.I. E EXERCE 0 } \\
\text { CONTROLE SOCIAL? }\end{array}$ & CONSELHEIROS & GESTORES \\
\hline Sim & $31,6 \%$ & $26,1 \%$ \\
\hline Não & $68,4 \%$ & $73,9 \%$ \\
\hline TOTAL & $100 \%$ & $100 \%$ \\
\hline Fonte: Elaboração própria. &
\end{tabular}

Assim, o CES/RJ, como instância de controle social, não funcionaria a contento, em razão de que a cultura política e a aproximação dos conselheiros com a definição de seu papel são questões ainda em aberto. Se, por um lado, após duas décadas de institucionalização do formato participativo no âmbito das estruturas do Poder Executivo, permanece a questão acerca da legitimidade e reconhecimento dos sujeitos políticos representantes de demandas da sociedade pelos decisores de políticas (policymakers); por outro lado, a dinâmica das variadas instâncias em que o controle social poderia efetivar-se (Reuniões Plenárias e Conferências de Saúde) traduzem atualmente o caráter altamente burocratizado das formas de accountability (Bohman, 1997; Lavalle e Castello, 2008; O’Donnell, 1998). É justamente nesse sentido que, para os conselheiros entrevistados, os representantes da sociedade não estão suficientemente capacitados para tomar decisões: são 68,4\% que responderam afirmativamente a essa questão.

A prática do controle social nas arenas políticas de deliberação governamental significou, para a sociedade política brasileira, uma das possibilidades de incidir os pleitos societários no processo de decisão de políticas. Nesse sentido, como bem ressaltaram Bispo Júnior e Gerschman (2013:12), compreender o papel cada vez mais forte (ou frágil) do demos no sistema político e nas arenas conselheiras de participação social remete à reflexão sobre o tipo de democracia à qual nos referimos.

\section{Considerações finais/conclusões}

Na última década do século XX, no Brasil, a fragmentação das demandas sociais pósdemocratização contribuiu para o surgimento de novos movimentos sociais - o MOPS, na década de 1970 e 1980 - que modificaram em inúmeros aspectos suas formas de mobilização social, incorporando novas demandas sociais (precarização das condições de trabalho, por exemplo) que encontraram uma grande dificuldade de penetração na arena política, nos governos nacionais, estaduais e locais e, naturalmente, por parte dos tomadores de decisão (policymakers).

Os conselhos de saúde institucionalizam-se nessa conjuntura social e política. Há autores que enfatizam que os conselhos são altamente institucionalizados, favorecendo uma linha de atuação que, em última instância, hierarquiza-se e legitima-se em função das ações do gestor. Ainda há visões que afirmam que as transformações operadas nos conselhos de saúde obedecem ao esvaziamento que se deu no papel político dos conselheiros da sociedade, colocando em xeque a própria dimensão associativa desses espaços. 
A questão de fundo, à qual se referiu grande parte deste artigo, não é que os novos movimentos sociais, após as lutas sociais e políticas pela democratização, acabaram por se institucionalizar. Em verdade, a atividade fundamental (a ação social na via do controle social) espelha uma relação Estado/Sociedade atravessada pelo jogo de escolhas de preferências no nível daquilo que os decisores políticos (policymakers), orientados pela lógica da máquina política governamental, consideram, no limite, como princípios do justo (fair) ou de justiça (fairness).

A pesquisa sobre o CES/RJ mostrou como, de certa maneira, na arena política de deliberação no Estado do RJ, os conflitos sociais e/ou políticos estão organizados segundo uma seletividade que lhes é impressa/plasmada pelo próprio Estado, portanto pelos representantes da SES/RJ; muito embora, como na gestão do secretário Gilson Cantarino, existisse uma postura mais proativa da própria SES/RJ em relação ao trabalho dos conselheiros. Assim, os decisores de políticas (policymakers), tal como na lógica da ação coletiva, procuram maximizar seus interesses - que correspondem aos projetos políticos do governo estadual - imprimindo às atividades dos conselheiros estaduais de saúde barreiras institucionais à sua efetiva ação política. Visto que aprovar/homologar um documento da SES/RJ (como o Plano Estadual de Saúde ou os Relatórios Anuais de Gestão) requer dos atores certa expertise no trato técnico das informações produzidas pelos gestores, a pesquisa demonstrou que os conselheiros de saúde sentem-se despreparados para esse processo de tomada de decisão pela falta de investimento na capacitação (ou educação permanente) dos sujeitos políticos. São exemplos desses tipos de informações: as de caráter jurídico e as sobre a complexidade do sistema de financiamento e orçamentário do SUS etc. Todas essas informações são percebidas pelos atores como de fundamental importância para a participação na tomada de decisão política. E, ao contrário do que se esperava, segundo os conselheiros entrevistados pela pesquisa, esses tipos de informações estão ausentes do trabalho cotidiano dos atores societais. O que a pesquisa com os conselheiros estaduais de saúde do Ri de Janeiro procurou salientar refere-se ao fato de que, sem autonomia política, o papel do sujeito político se fragiliza. Com isso, há, sem dúvida, uma impressão generalizada pelos conselheiros representantes da sociedade e dos profissionais de saúde de que a arena política do CES/RJ é secundarizada pelo Estado.

Diante desses dilemas, não só a prática do controle social pela via da participação social avança timidamente - sem que, com isso, os próprios sujeitos políticos, representantes de cidadãos de direito, possam influir nas decisões do Estado -, mas a própria prática da política reproduz (ou melhor, espelha) a decisão de uma minoria. Dessa forma, reedita-se uma forma de controle social em que o Estado procura (através de escolhas centralizadas no poder das classes políticas) dirigir a ordem social.

\section{Referências bibliográficas}

ABRUCIO, F.L. Os barões da federação: os governadores e a redemocratização brasileira. 2. ed. São Paulo: HUCITEC, 2002.

AVRITZER, L. Sociedade civil, instituições participativas e representação: da autorização a legitimidade da ação. Dados, vol. 50, n. 3, 2007.

BISPO JÚNIOR, J.P.; GERSCHMAN, S. Potencial participativo e função deliberativa: um de- 
bate sobre a ampliação da democracia por meio dos conselhos de saúde. Ciência \& Saúde Coletiva, vol. 18, n. 1, dez. 2013.

BOHMAN, J. Public deliberation: pluralism, complexity, and democracy. Cambridge: MIT, 1996.

BOSCHI, R. A arte da associação: política de base e democracia no Brasil. São Paulo: Vértice; Rio de Janeiro: IUPERJ, 1987.

BRASIL (CONSELHO NACIONAL DE SAÚDE). Resolução 196, de 10 de outubro de 1996. Brasília: Conselho Nacional de Saúde, 1996.

. Resolução 333, de 4 de novembro de 2003 - aprova as diretrizes para criação, reformulação, estruturação e funcionamento dos Conselhos de Saúde. Brasília: Ministério da Saúde/ Conselho Nacional de Saúde, 2003.

. Resolução 453, de 10 de maio de 2012 - aprova diretrizes para instituição, reformulação, reestruturação e funcionamento dos Conselhos de Saúde. Brasília: Ministério da Saúde, 2012 .

BRASIL (MINISTÉRIO DA SAÚDE). Lei 8.142, de 29 de dezembro de 1990 - dispõe sobre a participação da comunidade na gestão do Sistema Único de Saúde (SUS) e sobre as transferências intergovernamentais de recursos financeiros na área da saúde e dá outras providências. Brasília: Ministério da Saúde, 1990.

. Portaria 3.085, de 1 de dezembro de 2006 - regulamenta o Sistema de Planejamento do SUS. Brasília: Ministério da Saúde, 2006. Disponível em <http://bvsms.saude.gov.br/bvs/ saudelegis/gm/2006/prt3085_01_12_2006.html>. Acesso em 14 de junho 2011.

. Sistema de Planejamento do SUS: instrumentos básicos. 2. ed. Brasília: Ministério da Saúde, 2009a.

. Sistema de Planejamento do SUS: uma construção coletiva - formulação de políticas específicas de saúde. Brasília: Ministério da Saúde, 2009b.

CARVALHO, A. I. Conselhos de Saúde no Brasil: participação cidadã e controle social. Rio de Janeiro: FASE/IBAM, 1995.

CAWSON, A. Corporatism and Political Theory. Oxford: Basil Blackwell, 1986.

COELHO, V. S. A democratização dos conselhos de saúde: o paradoxo de atrair não aliados. Novos Estados, n. 78, jul. 2007.

CÔRTES, S. V. (Org.). Participação e saúde no Brasil. Rio de Janeiro: FIOCRUZ, 2009a.

. Sistema Único de Saúde: espaços decisórios e a arena política de saúde. Cadernos de Saúde Pública, vol. 25, n. 7, jul. 2009b.

CÔRTES, S. V.; GUGLIANO, A. Entre neocorporativistas e deliberativos: uma interpretação sobre os paradigmas de análise dos fóruns participativos no Brasil. Sociologias, n. 24, 2010.

DAGNINO, E. (Org.). Anos 90: política e sociedade no Brasil. São Paulo: Brasiliense, 1994.

. Confluência perversa, deslocamentos de sentido, crise discursiva. In: GRIMSON, A.

(Org.). La cultura en las crisis latinoamericanas. Buenos Aires: CLACSO, 2004.

DAHL, R. A. Poliarquia: participação e oposição. São Paulo: USP, 2005. 
DIAS, N. X. Conselho Estadual de Saúde do Rio de Janeiro: atuação e percepção dos representantes dos usuários [dissertação]. Rio de Janeiro: ENSP/FIOCRUZ, 2011.

DINIZ, E. Voto e máquina política: patronagem e clientelismo no Rio de Janeiro. Rio de Janeiro: Paz e Terra, 1982.

FALEIROS, V. P. et al. A construção do SUS: história da Reforma Sanitária e do processo participativo. Brasília: Ministério da Saúde, 2006.

FARIAS, C.F. Democracia deliberativa: Habermas, Cohen e Bohman. Lua Nova, n. 49, 2000.

FREIRE, A.; SARMENTO, C. E.; MOTTA, M. S. (Orgs.). Um estado em questão: os 25 anos do Rio de Janeiro. Rio de Janeiro: FGV, 2001.

GERSCHMAN, S. A democracia inconclusa. 1. reimpr. Rio de Janeiro: FIOCRUZ, 2004a.

. Conselhos Municipais de Saúde: atuação e representação das comunidades populares. Cadernos de Saúde Pública, vol. 20, n. 6, nov./dez. 2004b.

Formulação e implementação de políticas de saúde no estado do Rio de Janeiro. In: UGÁ, M. A. de. et al. (Orgs.). A gestão do SUS no âmbito estadual: o caso do Rio de Janeiro. Rio de Janeiro: FIOCRUZ, 2010.

. Democracia, políticas sociais e globalização: relações em revisão. In: ; VIANNA, M. L. W. (Orgs.). A miragem da pós-modernidade. Rio de Janeiro: FIOCRUZ, 2003.

; VIANNA, M. L.W. (Orgs.). A miragem da pós-modernidade. Rio de Janeiro: FIOCRUZ, 2003.

GIDDENS, A. Modernidade e identidade. Rio de Janeiro: J. Zahar, 2002.

GOULART, F. Dilemas da participação social em saúde no Brasil. Saúde em Debate, vol. 34, n. 84, 2010.

GRANOVETTER, M. The strength of weak ties. American Journal of Sociology, vol. 78, n. 6, may 1973.

HABERMAS, J. Mudança estrutural da esfera pública. Rio de Janeiro: Tempo Brasileiro, 1984.

HOCHMAN, G; ARRETCHE, M.; MARQUES, E. (Orgs.). Políticas públicas no Brasil.1. reimpr. Rio de Janeiro: FIOCRUZ, 2007.

LABRA, M.E. Análise de políticas, modos de policy-making e intermediação de interesses: uma revisão. Physis - Revista de Saúde Coletiva, vol. 9, n. 2, 1999.

. Conselhos de Saúde: dilemas, avanços e desafios. In: LIMA, N. T. et al. (Orgs.). Saúde e democracia: história e perspectivas do SUS. 1. reimpr. Rio de Janeiro: FIOCRUZ, 2005.

. Conselhos de Saúde do estado do Rio de Janeiro: complexidades e paradoxos do controle social. In: UGÁ, M. A. de et al. (Orgs.). A gestão do SUS no âmbito estadual: o caso do Rio de Janeiro. Rio de Janeiro: FIOCRUZ, 2010.

. É possível aferir a qualidade da representação dos usuários nos conselhos de saúde? Divulgação em Saúde para Debate, n. 43, jun. 2008.

; SILVA, O. F. As instâncias colegiadas do SUS no Estado do Rio de Janeiro e o processo decisório. Cadernos de Saúde Pública, vol. 17, n. 1, jan./fev., 2001. 
LAVALLE, A. G.; CASTELLO, G. Sociedade civil, representação e a dupla face da accountability. Caderno CRH, vol. 21, Bahia, 2008.

LESSA, C. O Rio de todos os brasis. Rio de Janeiro: Record, 2000.

MOREIRA, MR. Democratização da política de saúde [tese]. Rio de Janeiro: ENSP/FIOCRUZ, 2009.

MOTTA, M.S. Frente e verso da política carioca: o lacerdismo e o chaguismo. Estudos Históricos, n. 24, 1999.

. Mania de Estado: o chaguismo e a estadualização da Guanabara. História Oral, n. 3, jun. 2000 .

O’DONNELL, G. Accountability horizontal e novas poliarquias. Lua Nova, n. 44, 1998.

OLSON, M. A lógica da ação coletiva. São Paulo: USP, 1999.

OSORIO, M. Rio nacional, Rio local: mitos e visões sobre a crise carioca e fluminense. Rio de Janeiro: SENAC, 2005.

PAIM, J. Reforma Sanitária Brasileira: contribuição para a contribuição e crítica. Rio de Janeiro/Salvador: FIOCRUZ/EDUFBA, 2008.

PARADA, R. A construção do sistema estadual de saúde: antecedentes e formas de inserção. Physis - Revista de Saúde Coletiva, vol. 11, n. 1, 2001.

PEREIRA, E. O. Conselho Estadual de Saúde do Rio Grande do Sul: atores, conflitos e articulações - 1999-2002 [dissertação]. Porto Alegre: UFRGS, 2006.

PITKIN, H. F. The concept of representation. Berkeley: University of California, 1997.

RAKOVE, M. Don't make no waves... don't back no losers: an insider's analysis of the Daley machine. Bloomington: Indiana University, 1975.

RAWLS, J. O liberalismo político. 2. ed. São Paulo: Ática, 2000.

RIBEIRO, J. M. Conselhos de saúde, comissões intergestores e grupos de interesse no Sistema Único de Saúde (SUS). Cadernos de Saúde Pública, vol. 13, n. 1, jan./mar. 1997.

RIO DE JANEIRO (CONSELHO ESTADUAL DE SAÚDE DO RIO DE JANEIRO). Composição do Conselho Estadual: colegiado pleno. Disponível em < http://www.conselhodesaude.rj.gov. br/colegiado-pleno.html>. Acesso em 13 abril 2013.

. Regimento interno do Conselho Estadual de Saúde/RJ. Rio de Janeiro: CES/RJ, 2013.

SANTOS, M. A. B.; GERSCHMAN, S. O Sistema Único de Saúde como desdobramento das políticas de saúde do século XX. Revista Brasileira de Ciências Sociais, vol. 21, n. 61, jun., 2006.

SCHMITTER, P. Continúa el siglo del corporativismo? In: LANZARO, J. (Ed.). El fin del siglo del corporativismo. Bogotá: Nueva Sociedad, 1998.

SILVA, I. F. O processo decisório nas instâncias colegiadas do SUS no Estado do Rio de Janeiro [mestrado]. Rio de Janeiro: ENSP/FIOCRUZ, 2000.

SILVA, I. F.; LABRA, M. E. As instâncias colegiadas do SUS no Estado do Rio de Janeiro e o processo decisório. Cadernos de Saúde Pública, vol. 17, n. 1, Rio de Janeiro, jan./fev. 2001. 
STEINMO, S.; THELEN, K. Structuring politics: historical institutionalism in comparative analysis. Cambridge: Cambridge University, 1992.

STREECK, W.; SCHMITTER, P. Community, market, state - and associations? The prospective contribution of interest governance to social order. In: STREECK, W.; SCHMITTER, P. (Eds.). Private interest government: beyond market and state. London: SAGE, 1985.

TATAGIBA, L. F. Os conselhos gestores e a democratização das políticas públicas. In: DAGNINO, E. (Org.). Sociedade civil e espaços públicos no Brasil. São Paulo: Paz e Terra, 2002.

UGÁ, M. A. de et al. (Orgs.). A gestão do SUS no âmbito estadual: o caso do Rio de Janeiro. Rio de Janeiro: FIOCRUZ, 2010. 